\title{
JORNALISMO DE MODA - UMA ANÁLISE DOS EDITORIAIS DE MODA DA REVISTA ELLE BRA- SIL E ESTADOS UNIDOS
}

CRISTIANO MAX PEREIRA PINHEIRO

Universidade Feevale

Novo Hamburgo, Rio Grande do Sul, Brasil

e-mail:maxrs@feevale.br

CHRISTINE BAHIA OLIVEIRA

Universidade Feevale

Novo Hamburgo, Rio Grande do Sul, Brasil

e-mail: Christine@feevale.br

PATRÍCIA SODRÉ COSTA

Universidade Feevale

Novo Hamburgo, Rio Grande do Sul, Brasil

e-mail: patisodrec@hotmail.com

MILENA CHERUTTI

Universidade Feevale

Novo Hamburgo, Rio Grande do Sul, Brasil

e-mail:mcherutti@hotmail.com 
JORNALISMO DE MODA - UMA ANÁLISE DOS EDITORIAIS DE MODA DA REVISTA ELLE BRASIL E ESTADOS UNIDOS

Resumo: Tal estudo aborda a análise dos editoriais de moda, procurando avaliar como a revista Elle produz seus editoriais no Brasil e nos Estados Unidos. A metodologia utilizada foi a pesquisa exploratória, bem como desenvolve-se nesse estudo o jornalismo em conjunto com a moda. Ao analisar duas edições da Revista Elle Brasil e duas da Elle Americana, percebe-se que as semelhanças e diferenças entre as edições dos países. Palavras Chaves: Jornalismo; Moda; Análise de Editoriais; Revista Elle: Brasil e Estados Unidos.

\section{EL PERIODISMO DE MODA - UN ANÁLISIS DE LOS EDITORIALES DE MODA DE LA REVISTA QUE BRASIL Y ESTADOS UNIDOS}

Resumen: Este estudio aborda el análisis de los editoriales de moda, tratando de evaluar cómo la revista Elle produce it de editoriales en Brasil y Estados Unidos. La metodología utilizada fue exploratoria, así como ofertas con el periodismo y la moda. Después de revisar dos ediciones de Elle Brasil Revista y dos de Elle americana, que percibe las similitudes y diferencias entre los problemas de los países. Palabras clave: Periodismo; moda ; Análisis de imagen; Elle Magazine: Brasil y Estados Unidos de América.

FASHION JOURNALISM - AN ANALYSIS OF THE MAGAZINE'S FASHION EDITORIALS HE BRAZIL AND THE UNITED STATES

Abstract: This study addresses the analysis of fashion editorials, trying to assess how Elle magazine produces it's editorials in Brazil and the United States. The methodology used was exploratory, as well as deals with journalism and fashion.Afterreviewing two editions ofElleBrazil Magazineand two ofElleAmerican, itperceives the similarities and differences between the countriesissues. Keywords: Journalism; Fashion; Image Analysis; Elle Magazine: Brazil and United States of America. 


\section{INTRODUÇÃO}

A moda e as revistas femininas possuem uma ligação histórica, na qual suas inter-relações contribuíram para a consolidação de ambas, conforme argumenta Buitoni (1986). O mercado de revistas femininas é o segmento de maior destaque no país, tanto no número de publicações disponíveis, quanto por seu faturamento em vendas, reproduzindo um modelo de sucesso importado dos grandes centros. As revistas, principalmente as que dedicam maior ênfase à moda - como a revista Elle - fazem uso comumente do termo "editoriais de moda" para referirem-se à seção de moda que trata de tendências de vestimenta. Inclusive, referem-se a esta seção usando o termo editoriais de moda em seu espaço destinado ao editorial tradicional, no qual a diretora de redação da revista deixa sua "mensagem do mês", a qual está ligada à linha editorial da revista. Com seu conteúdo essencialmente visual, com material fotográfico o editorial de moda tem a missão de aproximar o leitor da revista fazendo com que se crie um relacionamento.

O presente trabalho propõe-se a estudar e analisar os editoriais de moda da revista Elle Brasil e Estados Unidos, umas das principais revistas de moda no mundo. Como também, tem como objetivo discutir sobre o jornalismo de revista, produções e editoriais, além de moda e imagem, tudo isso sempre voltando ao tema de como a moda é importante para comunicar.

O principal objetivo deste estudo é descobrir quais as diferenças e semelhanças de uma revista da mesma empresa, porém, de diferentes países e leitores. Assim, será possível diferenciar como cada uma produz editoriais de moda e tendências para se comunicar com seus leitores.

Para atender tal proposta, este trabalho foi dividido em duas seções, onde a primeira aborda os conceitos de jornalismo, jornalismo de revista, jornalismo de moda e editorial e produção de moda. Já na segunda, foram abordados os temas de moda e moda e imagem. Para realização deste trabalho, autores como Joffily (1991), Lage (2003), Vilas Boas (1996), Scalzo (2004) et al, foram referencionados.

\section{JORNALISMO}

O Jornalismo é a síntese do espírito moderno: a razão (a "verdade", a transparência) impondo-se diante da tradição obscurantista, o questionamento de todas as autoridades, a crítica da política 
e a confiança irrestrita no progresso, no aperfeiçoamento contínuo da espécie (MARCONDES FILHO, 2002).

Segundo Rossi (2000), o jornalismo é uma fascinante batalha pela conquista das mentes e corações de seus alvos, sejam eles leitores, telespectadores ou ouvintes. Uma batalha geralmente sutil que usa uma arma de aparência extremamente inofensiva: a palavra. $O$ autor aponta ainda que a imprensa não vive apenas dos episódios ocorridos num determinado dia, mas também da discussão, do debate e da análise de acontecimentos ou situações intemporais - ou seja, que estão acontecendo, e não simplesmente que aconteceram.

A definição dos gêneros jornalísticos é um dos assuntos mais polêmicos e dedifícil estudo dentro da comunicação. Um dos maiores estudiosos da área, oprofessor José Marques de Melo dividiu o jornalismo em cinco gêneros: informativo, opinativo, interpretativo, diversional e utilitário ou de prestação de serviço.

O jornalismo opinativo delimita onde o jornalista ou o jornal podem emitiropinião, uma vez que um dos pilares do jornalismo é a busca pela imparcialidade, atransmissão do fato de forma mais direta possível. A opinião do jornalista, "entendido como profissional regularmente assalariado e pertencente aos quadros da empresa", geralmente aparece no editorial, como também em comentários, resenhas e crônicas (MELO 2003).

Segundo Melo (2003), o gênero interpretativo pode ser definido por gênero explicativo, o qual trata do jornalismo profundo, de análises e perfis. Considera-se, também, o conceito de "New Journalism", que admite maior enfoque mais imaginativo e lírico à reportagem, permitindo ao jornalista inserir-se na narrativa sem alterar a realidade da notícia sobre a qual trabalha. Remetendo ao tema deste trabalho, o jornalismo interpretativo também está presente nos perfis de figuras do meio e em análises de desfiles e tendências.

Já o informativo, consiste no gênero mais clássico do fazer jornalístico, uma vez que tem oobjetivo principal de informar. Dentro do informativo estão a nota, a notícia, a reportagem e a entrevista - e não se excluem as reportagens e notícias de moda.

Mas os dois gêneros que melhor se encaixam no jornalismo de moda são o diversional e o utilitário. O primeiro tem relação com o divertimento e o emocional, caracterizado por reportagens mais profundas, sem muito 
interesse no furo e no "hard news". Consiste no jornalismo que acaba servindo como entretenimento ao leitor. Já o gênero utilitário tem o objetivo de informar o leitor sobre questões práticas da vida. Seu principal objetivo é orientar o receptor, com informações úteis e próprias, o caracterizando como um gênero independente (VAZ, apud ASSIS; MELO, 2010, p.126).

De acordo com a visão devidamente ampliada sobre jornalismo, decorrente as informações contidas nesta seção, o objeto central deste estudo será introduzido nas próximas partes.

\subsection{JORNALISMO DE REVISTA}

O jornalismo de revista admite caráter de entretenimento, divertindo os leitores. Uma revista é um veiculo de comunicação, um produto, uma marca, um objeto, um conjunto de serviços, uma mistura de jornalismo e entretenimento. De acordo com Scalzo (2004), a revista é "uma história de amor com o leitor". E, como toda a relação, também precisa de confiança, credibilidade, expectativas, erros, pedidos de desculpas, brigas e reconciliações.

As revistas nasceram para abranger a um público específico. Desse modo, a linguagem, tanto textual/editorial quanto visual, é um dos elementos que vive em constante evolução e modificação para acompanhar as demandas dos leitores. Ao longo do século XIX, as revistas cresceram e ditaram moda, abrindo caminho para outros estilos (MIRA, 2001).

Scalzo (2004), ainda afirma que a revista é caracterizada por ser um informativo mais completo que um jornal e menos do que um livro, por possuir textos mais aprofundados que os dos jornais, com características literárias, já que em seus textos, além de muitos detalhes, possuem trechos de músicas, poemas, ditados populares. O maior diferencial da revista está em seu visual, uma mistura de cores, imagens e informações que entretêm leitores e principalmente leitoras, fazendo com que as colecione. A sua durabilidade também é outro diferencial, devido à qualidade do papel e da impressão.

Por essas afirmações, é possível perceber que a revista trata o leitor de uma maneira mais íntima, e, para isso, precisa saber ouvi-lo. São diversas as maneiras que permitem ocorrer esta troca: pesquisas qualitativas e quantitativas, telefonemas, cartas e e-mails enviados à redação. Um bom editor consegue manter uma relação estreita com determinado público e, muitas vezes, sabe antes do leitor o que tal segmento de mercado quer ou vai querer ler, pois, só assim a revista será capaz de adiantar e surpreender. 
Boas (1996) destaca que, como há mais tempo para preparar o conteúdo das revistas, os textos devem ser mais criativos, com mais recursos estilísticos, diferentemente do que se vê no jornalismo diário, quando a velocidade com que se precisa trabalhar a informação faz com que o texto se baseie muito mais na forma padrão de escrever, usando na maioria dos textos apenas o estilo informativo.

Como visto anteriormente, no jornalismo existem diversas temáticas, assimcomo acabamos de ver sobre o jornalismo de revista. Agora que já conhecemos, vamos falar sobre o Jornalismo de Moda que é o objetivo principal deste trabalho.

\subsection{JORNALISMO DE MODA}

Joffily (1991) indica que a moda é uma das maiores fontes de faturamento, via publicidade, da mídia eletrônica, e "na mídia impressa, é o principal atrativo para o público leitor feminino em um enorme número de publicações". Segundo ela em alguns jornais, a moda não recebe status de uma editoria, permanece como uma seção, sem especialidade, semelhante às de passatempos, palavras cruzadas, fofocas da cidade.

A moda tem seu lado de charme, de feitiço. Esse aspecto torna-se às vezes tão ofuscante que oculta outro lado vital: a moda também é trabalho. "É uma cadeia que se estabelece desde a prancheta do estilista, passando pelos complexos industriais, com seus operários, até as lojas e campanhas publicitárias" (JOFFILY, 1991).

Segundo Hinerasky (2010), a entrada do país no circuito demoda se deu no final dos anos 90, como resultado do crescimento do setor têxtil.

\footnotetext{
Valorização da moda como negócio, qualidade da matéria prima nacional (e o seu aprimoramento), a utilização e os investimentos em tecnologia de ponta; a criatividade dos estilistas [...], a consolidação de um calendário de moda uniformizando as iniciativas antes isoladas, aliadas à cobertura e repercussão na imprensa especializada no Brasil e exterior (HINERASKY, 2010).
}

O papel da imprensa de moda seria mediar o que acontece na passarela para o grande público e esse trabalho é imprescindível para o bom funcionamento da indústria da moda. E um bom jornalista de moda deve conhecer bem a mesma, suas raízes, como evoluiu, como foi influenciada e suas histórias em geral, para entender as aspirações dos estilistas e conseguir 
contextualizar para os leitores - e o gosto pessoal precisa ser deixado de fora. "Uma frase apenas pode por em risco a carreira do estilista" (PEZZOLO, 2006, p.70).

Contudo, as imagens também consistem na linguagem das publicações de moda, afinal, os leitores precisam ver na prática o que os textos falam para que façam sentido - uma imagem pode, inclusive, substituir o texto descritivo. E os editoriais - seções de fotos realizadas com vestimentas selecionadas pelos jornalistas de moda para sintetizar uma ideia, onde é possível misturar marcas, apontando as semelhanças e diferenças das peças dentro do estilo proposto -, traduzem a necessidade das imagens nas revistas de moda. Portanto, os editoriais se tornaram em "fotos que seriam persuasivas - ou sugestivas; recheadas de ilusão eimaginação, elas estimulam, induzem, conduzem" os leitores a reproduzi-las (BUITONI, 1990).

Após vermos sobre o jornalismo, jornalismo de revista e jornalismo de moda,agora, partimos para Editorial e Produção de Moda e editoriais, do qual também seráo foco deste trabalho de análise da revista.

\subsection{EDITORIAL E PRODUÇÃO DE MODA}

Segundo Siegel (2008) a forma mais utilizada para as marcas divulgarem seus produtos atualmente, é o editorial de moda. Ele consiste, numa seção, ou publicação, em jornais, revistas ou periódicos que objetivam exaltar conceitos e comportamentos via ensaios fotográficos com imagens fortes e marcantes. Propicia para o criador, alta credibilidade, segmentação, consolidação, exposição de detalhes.

Um editorial de moda não existe apenas para apresentar ao mercado o produto à disposição, mas também realiza críticas, aponta as ligações da moda num sentido mais amplo com a atualidade sociocultural e avalia as propostas dos estilistas. Já uma produção de moda é uma composição que organiza elementos na busca de um estilo, ou mais concretamente, de certo climaglobal da foto que traduza um estilo (JOFFILY, 1991).

Conforme Piovan e Newton (2003), para realizar um editorial, independente da linha da publicação, é imprescindível contar com profissionais de diferentes áreas, como produtores de moda da marca/produto que irão elaborar a matéria selecionando os "looks" e acessórios, contextualizando a proposta e conceito para determinada coleção, a editora, que conhece o estilo, as preferências, necessidades e anseios de seu público-alvo, os mode- 
los, que posarão para asimagens, os cabeleireiros e maquiadores, que irão realizar a maquiagem dos modelos eo fotógrafo, que geralmente é escolhido pelo estilo em que se trabalha, se condiz ou não com o conceito da marca e revista fotografada.

Logo, produtores, editores, e diretores escolhem as imagens que meIhor conceituam a ideia da marca/produto e encaminham para aarte final, na qual é realizada a composição das fotos com textos nas páginas. Após tal processo, é obtido o visual final da matéria que constará na revista (JOFFILY,1991).

Após vermos sobre jornalismo, jornalismo de revista, jornalismo de moda e editorial e produção de moda, partimos para o tema "moda" mais focado em seu conceito.

\section{MODA}

A partir da era medieval que o termo moda surgiu, quando a ideia de grandes mudanças em pouco tempo não era muito comum, conceito que mudou durante o século XX. E é nesta era, que se pode falar em moda surgindo como um sistema (LIPOVETSKY, 1994). Ela teria aparecido no início do Renascimento, ancorada pelo mercantilismo capitalista.

Com a Revolução Industrial do século XIX, relacionou-se a liberdade da vida cotidiana com o desenvolvimento do individualismo, e a moda como expressão do indivíduo. Em um mundo dominado pela primeira vez por máquinas, o capitalismo atingiu um novo nível, criando grandes centros turbulentos nas cidades, com novas características Assim, a moda passou a ser mais importante do que antes. A diferença das alamedas calmas dos séculos anteriores para as ruas turbulentas da nova geração era assinalada pelas roupas, cada vez mais marcantes da distinção entre o "estar em casa" e o “estar em público" (WILSON, 1985).

Com a moda, aparece uma primeira manifestação de uma relação social que encarna um novo tempo legitimo e uma nova paixão própria ao Ocidente, a do "moderno". A novidade tornou-se fonte de valor mundano, marca de excelência social; é preciso seguir "o que se faz" de novo e adotar as últimas mudanças do momento: o presente se impôs como o eixo temporal que rege uma face superficial, mas prestigiosa da vida das elites (LIPOVETSKY, 1989, p.33). 
Hoje, a moda segundo Braga (2006) é uma espécie de auto-rejeição, pelos motivos dela sempre estar se reinventando em curtos espaços de tempo. $O$ autor ainda cita que moda é um processo que abrange a questão da criação por excelência, tangenciando a arte e a estética, o que também lhe dá a condição de estratificadora social.

Podemos assim dizer que a moda possui diversas funções dentro da sociedade, serve como proteção, como linguagem para comunicação entre os seres, e também como um sistema próprio de organização dentro da sociedade. Cada sociedade determina de acordo com a sua cultura, os modos de vestir dos diferentes indivíduos e grupos que a compõem.

Em contrapartida, Treptow (2005) afirma que a moda passa pelas seguintes fases: lançamento, aceitação, cópia e desgaste. Mas para que isso aconteça, é necessário um censo comum e que as pessoas acreditem, concordem e consumam uma ideia para que ela se torne moda. Este consenso entre as pessoas é denominado uma tendência de moda, as quais são influenciadas por crenças comuns entre os indivíduos.

Portanto, a imagem, a mídia e o marketing assumem lugares privilegiados no mundo da moda, pois são responsáveis por comunicar, anunciar e transmitir as novidades para o consumidor. "Quanto mais eficiente se constrói e se comunica um conceito, mais projeção marca e produto conseguem" (MESQUITA, 2004, p. 90).

A partir destes conceitos sobre moda, partimos para Moda e Imagem, no qual teremos mais bases de como é feito um editorial de moda, que é o tema principal deste trabalho.

\subsection{MODA E IMAGEM}

Até o início do século $\mathrm{XX}$, a moda era retratada em revistas através de ilustrações feitas por desenhistas. A primeira fotografia de moda foi feita em 1892, na revista parisiense "La mode pratique", com o procedimento de fotogravura, que consistia em ter escrita e imagem, em um mesmo papel. Portanto, tais imagens poderiam também ser chamadas de "fotografias de gente na moda", pois não apresentavam certa "apresentação do produto ou da marca que hoje nós consideramos indispensável para definir este gênero da fotografia." (MARRA, 2008, p. 83).

Conforme explicam Custódio e Souza (2005) "a fotografia de moda era a interpretação do universo luxuoso e moderno que cercava esse mundo", 
onde as poses das modelos imitavam posturas da pintura renascentista. A partir do Pós-Guerra as revistas de moda passaram a ter grande importância na divulgação das novas coleções europeias e, com esse crescimento, as exigências impostas aos fotógrafos se tornaram mais maleáveis, e esses profissionais puderam colocar mais criatividade e ideologias nas suas produções. Assim, a fotografia de moda cresceu, diferenciou-se, e foi evoluindo junto com a sociedade, se tornando um registro inclusive de mudanças socioculturais.

Tratando disso, Kossoy (2002) afirma que a fotografia de moda é:

Uma fantasia que é tornada realidade concreta uma vez que veiculada pela mídia e consumida enquanto produto. [... ] Com a foto de moda consome-se, ao mesmo tempo, dois produtos que se mesclam num todo indivisível: a roupa, o vestuário propriamente dito e o seu entorno, o mundo ficcional (apenas na aparência) que envolve a cena, a situação, a pose, o gesto. Nesse processo consome-se um estilo, uma estética de vida codificada no conteúdo da representação. (KOSSOY, 2002, p.52).

No mundo da moda, não somente os estilistas são estrelas, mas também os fotógrafos de moda, que são os realizadores de imagens inovadoras que os ajudam a alcançar sua condição de ícones. Atualmente, a fotografia de moda é o gênero mais inspirado e criativo da fotografia comercial. As revistas de grandes nomes da moda são como se fossem bíblias e uma das principais fontes de inspiração para o universo fashion ${ }^{1}$. Elas contêm a chave das tendências mais atuais e são o trampolim dos fotógrafos de moda mais inspirados e atuais (SIEGEL, 2008).

Após analisarmos os termos citados acima, temos base para seguir para a análise dos editoriais das revistas Elle americana e brasileira.

\section{OBJETO DE ESTUdo E ANÁLISE}

Por questão de acessibilidade, foram escolhidas as edições dos meses de setembro e outubro de 2013, da revista Elle brasileira e americana, tendo como principal indicador de análise, as diferenças e semelhanças dos editoriais e capa de uma mesma empresa de revista, porém de países diferentes.

A pesquisa do trabalho se dá por meio da análise da teoria conceitual

A palavra fashion significa moda em inglês. 
da moda e do entendimento de como o jornalismo de moda é definido nos dias atuais, e com isso traçar um paralelo com a moda como comunicação. Será realizada uma pesquisa exploratória para este trabalho, na qual serão identificadas as diferenças e semelhanças de ambas as edições.

Segundo Prodanov (2009), pesquisa exploratória é aquela que tem como finalidade proporcionar mais informações sobre o assunto, "possibilitando sua definição e seu delineamento, isto e, facilitar a delimitação do tema de pesquisa". Com isto, a pesquisa deste trabalho será secundária, bibliográfica, através de consultas em livros que possam complementar as teorias que serão estudadas na qual se busca saber o padrão dos editoriais e o método de abordagem com as leitoras da revista Elle Brasil é o mesmo usado na Elle americana, se há um método padrão para os editoriais em ambas as edições.

\begin{abstract}
A pesquisa bibliográfica é aquela elaborada a partir de material já publicado, constituído principalmente de livros, revistas, publicações em periódicos e artigos científicos, jornais, boletins, monografias, dissertações, teses, material cartográfico, Internet, com o objetivo de colocar o pesquisador em contato direto com todo o material já escrito sobre o assunto da pesquisa (PRODANOV, 2009).
\end{abstract}

Ao elaborar a análise desta pesquisa, foram utilizados os conceitos da autora Bardin (1997), que explica as fases de uma análise: a pré análise, a exploração do material e o tratamento e a interpretação dos resultados.

(A pré análise) é a fase de organização propriamente dita. Corresponde a um período de intuições, mas, tem por objetivo tornar operacionais e sistematizar as ideias iniciais, de maneira a conduzir a um esquema preciso do desenvolvimento das operações sucessivas, num plano de análise. Recorrendo ou não ao ordenador, trata-se de estabelecer um programa que, podendo ser flexível (quer dizer, que permita introdução de novos procedimentos no decurso da análise), deve, no entanto, ser preciso. Geralmente, esta primeira fase possui três missões: a escolha dos documentos a serem submetidos à análise, a formulação das hipóteses e dos objetivos e a elaboração de indicadores que fundamentem a interpretação final (BARDIN, 1997, p.95).

As categorias jornalismo, jornalismo de revista, jornalismo de moda, jornalismo e produção de moda, moda e imagem serão inseridas nesta análise. 


\subsection{Elle Magazine}

A publicação francesa teve seu primeiro número publicado em 21 de novembro de 1945, na delicada época do pós guerra. Os fundadores Pierre Lazareff e sua esposa Hélène Gordon passaram os anos anteriores nos Estados Unidos e retornaram a Paris com o intuito de criar uma revista feminina que fosse "séria dentro da frivolidade e irônica perante o grave", como declarou Hélène à época do lançamento. A proposta foi um sucesso e vendeu já na primeira edição 70 mil cópias.

Em 1969, Elle ganhou a primeira edição internacional, a Elle Japão. Nos anos 1980, fixou-se em vários países, entre eles os Estados Unidos, Inglaterra, Suécia e, em 1988, o Brasil. Com seu crescimento, a publicação agora dá nome às revistas específicas, como a Elle Girl (para adolescentes) e a Elle Decor. Elle está presente em 41 países, com uma tiragem de quase dois milhões de exemplares e com um público de mais de 20 milhões de leitoras.

No Brasil, a presença de Elle também é muito forte. Além de serem responsáveis por uma fatia de 235 mil leitores, que são, em média, mulheres das classes A e B, a publicação ainda aposta em site na internet, premiações e, mais recentemente, em um desfile de moda que acontece em um ponto turístico - em 2012, o palco do evento foi a Ponte Estaiada, em São Paulo.

A Elle é uma revista que dá ênfase a todos os aspectos da moda, da arte à música, explicando quais são as relações com a moda e dando ferramentas às leitoras para que elas mesmas possam descobrir a origem das tendências que usam a cada dia. Há também perfis de fashionistas e designers e editoriais de moda com peças caras - como um vestido de 11 mil reais que aparece na edição de maio.

Destaca-se de Vogue por colocar todos os preços e pela preferência por textos mais didáticos. 


\subsection{REVISTA ELLE BRASIL - SETEMBRO 2013}

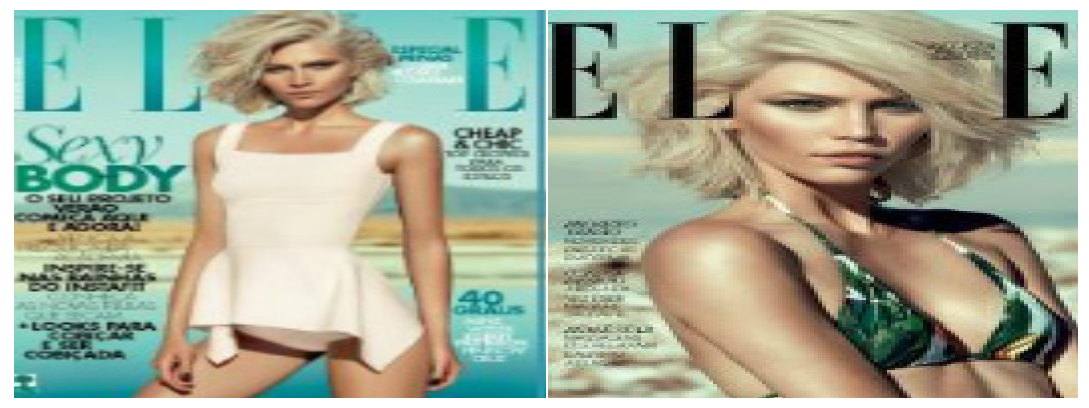

Figura 1 - Capa revista Elle Brasil e foto abertura matéria Fonte: Revista Elle Brasi

A capa admite tons de verde em um cenário de praia, contendo oito chamadas para os principais assuntos, onde o em maior evidência é sobre "Sexy Body" (corpo sexy). O nome da modelo não aparece, e ela veste uma espécie de maiô branco com modelagem “peplum” na cintura. Já a primeira página da admite o nome da revista ao fundo, porém desta vez aparece o nome da modelo: Maria Clara Povia. Nela contém três chamadas, entre elas "Projeto Verão", "Corpo Desejo" e "Bem-Estar", a modelo aparece somente da cintura para cima na foto, usando um biquíni, sob um fundo desfocado de uma praia.

O editorial consiste em sua maioria por fotos da modelo usando biquíni, apresentando seu corpo magro e bem cuidado, com exceção da última foto, na qual a modelo Thais Schreiner veste peças mais formais. Ele também, intercala imagens com os textos das matérias, sobre saúde, exercícios e formas para se obter o "corpo desejado". Fotos: Eduardo Rezende. Produção de moda: Rita Lazzarotti

\subsection{REVISTA ELLE ESTADOS UNIDOS - SETEMBRO 2013}
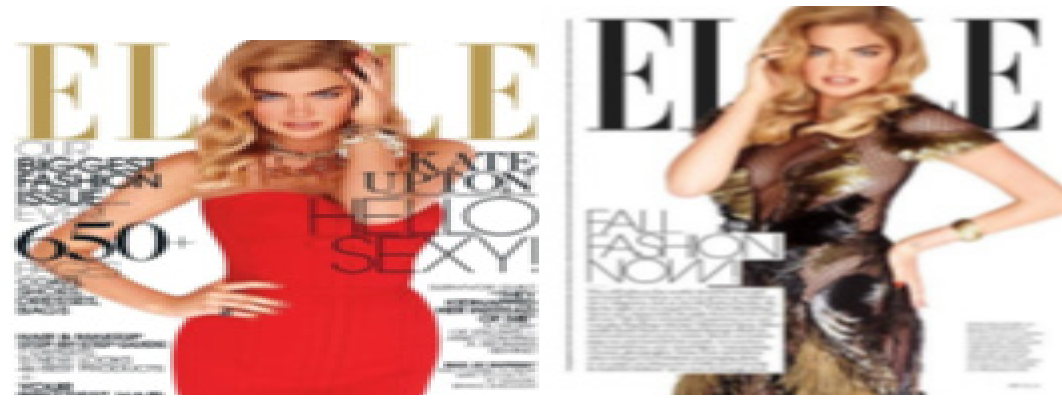

Figura 2 - Capa Revista Elle Americana e abertura editorial Fonte: Revista Elle Estados Unidos 
Na capa, a modelo Kate Upton aparece usando um vestido vermelho justo, com colares e pulseiras grandes e douradas, em um fundo branco. A chamada principal: "Hello Sexy" (Olá sexy). A capa contém mais seis chamadas dos principais assuntos. Já a primeira página consiste na chamada para o editorial "Fall Fashion Now", onde a modelo utiliza um vestido com transparência e detalhes pretos e dourados e uma pulseira dourada. O fundo é branco e as letras são pretas. Marcas: Gucci e David Yurman.

As fotos da modelo mundialmente conhecida Kate Upton foram tiradas dentro de uma casa, apresentando roupas glamorosas, de marcas renomadas. O editorial possui sete fotos da modelo e duas páginas contendo a entrevista realizada com a mesma, onde traz um breve resumo de sua carreira como modelo de biquíni, comentários sobre sua vida particular, trabalhos e amor. Todas as marcas utilizadas foram descritas, como também a equipe de produção. Fotos: Carter Smith. Produção de moda: Joe Zee.

\subsection{REVISTA ELLE BRASIL - OUTUBRO 2013}

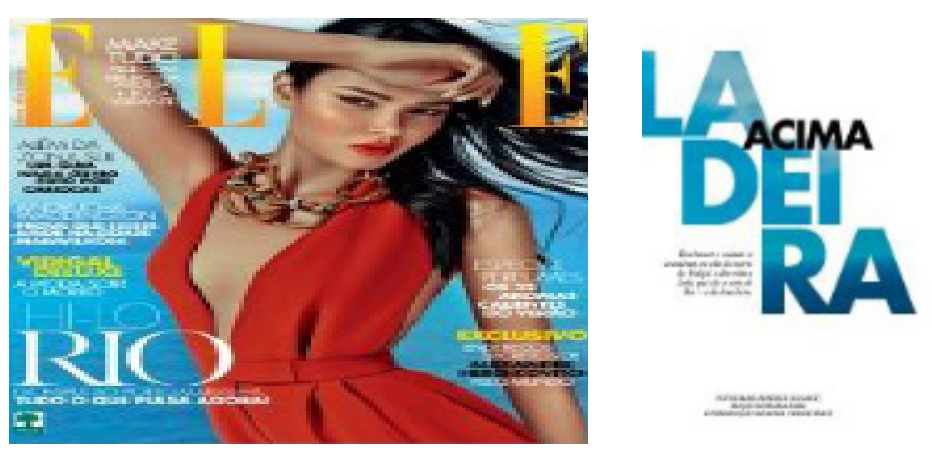

Figura 3 - Capa revista Elle Brasil e título do editorial "Ladeira Acima" Fonte: Revista Elle Brasil

A capa admite como fundo o mar e o céu desfocados, a modelo ao centro com uma das mãos no rosto, e usando vestido decotado vermelho com um máxi colar dourado. A chamada principal é "Hi-Lo RIO, da barra ao Porto Maravilha, tudo o que pulsa agora", contendo mais seis chamadas para outras matérias. Letras com as cores laranja, branco, preto e amarelo. Já a primeira página, branca, com o título "Ladeira acima" e uma chamada para a moda "beachwear" e "couture" no alto do morro do Vidigal/RJ. Letras em azul e preto.

O editorial acontece no cenário do alto do Vidigal no Rio de Janeiro, apresentando muita cor, estilo, estampas e atitude. Ele contém apenas fo- 
tos, abrangendo o total de dez páginas que contrastam a realidade da favela com o fundo do litoral da cidade. Há descrição das marcas das peças utilizadas. Fotos: Fabio Bartelt. Produção de moda: Thiago Biagi.

\subsection{REVISTA ELLE ESTADOS UNIDOS - OUTUBRO 2013}
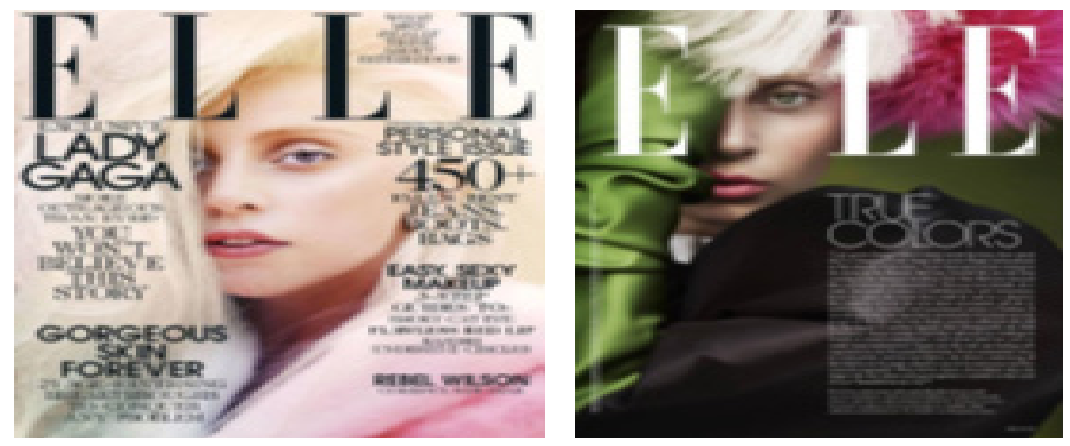

Figura 4 - Capa revista Elle Estados Unidos e abertura editorial “True Colors" Fonte: Revista Elle Estados Unidos

A capa apresenta como modelo a cantora pop Lady Gaga e ao lado esquerdo apresenta-se a chamada do editorial principal (Lady Gaga). Mais cinco chamadas dos principais conteúdos da revista estão situados acima da foto do rosto da cantora. As cores utilizadas para a foto foram predominantemente brancas com letras pretas. Já a primeira página consiste na capa do editorial, onde contém somente do rosto de Gaga, porém mais colorida, em tons de verde, branco, rosa e pretos o texto em branco. Há um pequeno texto, nomeado de "True Colors" (Cores verdadeiras). Descrição de moda: Vestido de lã com gola e mangas de cetim de seda e peruca rosa. Marcas: Elsa Schiaparelli by M. e Christian Lacroix.

Admitindo como modelo principal a cantora pop Lady Gaga, o editorial constou com nove fotos, com efeitos que se misturam entre paredes e folhagens verdes, como também reflexos. As cores predominantes estão entre o rosa claro, branco e verde. Tal também contém uma página com a chamada da matéria e duas de entrevista, que foi feita no restaurante do pai de Lady Gaga, relatando um breve resumo da vida da cantora. Há descrição das marcas utilizadas, como também da equipe de produção. Fotos: Ruth Hogben. Produção de moda: Brandon Maxwell.

\subsection{ANÁLISE DAS EDIÇÕES BRASILEIRA E AMERICANA}


Baseando-se nos estudos e leituras feitas sobre jornalismo de revista, e considerando as observações das edições da revista Elle de setembro, pode-se notar que ambas possuem um padrão estético muito parecido, porém, por serem publicações veiculadas em diferentes países (Brasil e Estados Unidos), a forma de abordagem na questão do tema do editorial principal (mesma modelo usada na capa), é bem diferente uma da outra. Assim como Scalzo (2004, p.37), afirma que hoje as grandes revistas femininas seguem modelos muito parecidos e, apesar de cada uma direcionar-se para um tipo específico de mulher, remetem fórmulas e cobrem mais ou menos o mesmo universo.

Portanto, a revista Elle americana, admite um editorial de moda com uma modelo famosa, juntamente com uma entrevista de duas páginas. Quando na edição brasileira, o editorial com a modelo da capa caracterizou-se como um guia de emagrecimento, juntamente com fotos que não chegam a ser um editorial de moda, porém, o assunto é muito válido para a época do ano no país, onde as mulheres procuram saber sobre regimes e tratamentos estéticos para chegar ao verão em forma. Com referência nas leituras feitas sobre jornalismo de moda, analisa-se a forma de exploração de texto e imagem. Neste caso, a edição americana continha duas páginas de texto reportagem e a brasileira três páginas de textos sobre corpo, dieta e atividades físicas, uma página para cada assunto. Na americana, nota-se que consiste em um editorial mais ligado ao glamour, com marcas caras, onde a modelo expressa tal proposta de glamour que o editorial quer passar. Já a edição brasileira admite uma proposta diferente, onde as imagens e expressões das modelos ressaltam um estilo de vida mais saudável, apresentando preocupações com o corpo.

Considerando a produção de moda, cada revista prioriza aquilo que vende, juntamente com a novidade e o que as leitoras querem ver e se inspiram. A revista americana admitiu a modelo Kate Upton, uma personagem famosa e reconhecida como grande fonte de inspiração das mulheres americanas. Já a edição brasileira, não se preocupou com a modelo fotografada, mas sim com a matéria relacionada aos estereótipos de corpo desejado nessa época do ano. Os assuntos e formas de abordagem dos editoriais admitiram caráter diferente, porém, ambos buscaram sua identidade na produção de moda, utilizando recursos e elementos coerentes a fim de dialogar com o público alvo (JOFILLY, 1991).

Ambas as edições priorizam a qualidade e detalhes das fotos, admitindo 
o conceito de moda e imagem, a fim de transmitir a mensagem que o editorial pretendia passar. Todavia, a edição americana apresentou as marcas juntamente com valores das peças, já a brasileira, por possuir proposta diferente, demonstrou apenas as marcas das peças utilizadas.

Já nas edições de outubro da revista Elle brasileira e americana, baseando-se no jornalismo de revista, nota-se, novamente, o padrão estético similar, principalmente na capa, onde as edições mantiveram um padrão de letra e caracterizaram-se por fotos grandes e modelos chamativas. Segundo Goulart (2006), "texto e imagem, traduzidos em matéria bem escrita e apresentação visual eficiente, são as bases da revista”, o que é visível em ambas as edições. Como também, elas admitem maior atenção ao editorial principal, utilizando grande quantidade de fotos, porém a brasileira não contém textos.

Considerando a definição de jornalismo de moda, nota-se que ambas as edições priorizaram um editorial de moda com marcas caras e grande quantidade de fotos. Porém, na revista americana, foi utilizada uma figura mundialmente conhecida, a cantora Lady Gaga, e a Elle brasileira fez uso de uma modelo profissional, transferindo maior atenção ao cenário utilizado para as fotos, a favela do Vidigal. Segundo Jofilly (1991), o jornalismo de moda têm o objetivo de adequar o sonho da moda à realidade da leitora, e dar à ela o direito de se apropriar do sonho no seu dia-a-dia.

Com base nas leituras sobre produção de moda, pode-se analisar que no editorial da Elle americana, as fotos admitem caráter de ficção, com desfoques, mostrando a roupa, porém ela não é necessariamente o foco principal, e o editorial ainda possui duas páginas de texto sobre a cantora. Diferentemente do editorial brasileiro, o qual possui fotos com o objetivo principal de produção de roupa, a fim de que a leitora se identifique, sem páginas contendo textos, com foco apenas na moda.

Enfim, na categoria moda e imagem, ambas as edições descreveram produções de estilistas bem conceituados juntamente com os valores das peças, admitindo contribuir como um forte instrumento de comunicação nos editoriais. Siegel (2008) admite que as revistas de moda são como bíblias, tornando-se uma das principais fontes de inspiração para o universo fashion.

Após analisar tais edições da revista Elle, podemos concluir que existem semelhanças e diferenças. A americana seguiu o mesmo padrão de editorial nas edições de setembro e outubro, na qual foram utilizadas duas celebri- 
dades mundialmente conhecidas e foram produzidas fotos com roupas de marcas caras, e duas páginas de textos sobre as personagens. Já a brasileira não admitiu um padrão em nenhuma das edições analisadas, onde a revista de setembro deu foco para o corpo, com textos e poucas fotos, sem destaque para marcas, e a edição de outubro fez o uso de muitas fotos, com destaque para a produção de moda, com descrição de marcas e valores das peças, porém, sem textos. 


\section{CONSIDERAÇÕES FINAIS}

Atualmente, no mundo da moda, a forma mais utilizada para as marcas divulgarem seus produtos, é o editorial de moda. Com ele, as revistas exaltam conceitos e comportamentos através de ensaios fotográficos com imagens fortes e marcantes. Como Siegel (2008) aborda, é desta maneira que propicia ao criador, uma alta credibilidade, segmentação, consolidação e exposição de suas peças em detalhes, entre outros, atingindo o público alvo, de uma maneira fácil e certeira.

Então, a hipótese que teve como objetivo analisar os editoriais da revista Elle americana e brasileira, e descobrir se há semelhanças e diferenças de uma revista da mesma empresa, porém de diferentes países, e se elas mantêm um mesmo padrão de abordagens com suas leitoras ou não. Conclui-se que há sim diferenças e semelhanças, principalmente na questão estética da revista, que é um padrão quase que idêntico. Já nos editoriais, notaram-se mais diferenças entre as revistas, desde a questão da escolha de modelos, onde nos Estados Unidos, opta-se por figuras públicas conhecidas, e no Brasil, geralmente opta-se por modelos fotográficas que não são famosas. Além da questão do assunto do editorial principal, onde no Brasil nem sempre é um editorial de moda, e sim, matérias com poucas fotos e não focadas necessariamente no ramo fashion.

Apesar de muitas pessoas tratarem a "moda" como algo fútil, ela está inserida em nosso meio social, em variados tipos de sujeitos, classes, idades, culturas, e em tudo o que esta em nosso redor. A moda é comunicação e comportamento, e o meio que melhor comporta tais mudanças consiste na revista feminina, por conhecer bem o seu público alvo.

Por fim, deixa-se a expectativa de trabalhos subsequentes a este, a fim de mostrar outros olhares sobre jornalismo e moda, e mostrar a importância deste tema nos dias de hoje, uma vez que não temos muita bibliografia sobre $o$ assunto em questão. 


\section{JORNALISMO DE MODA - UMA ANÁLISE DOS EDITORIAIS DE MODA DA REVISTA ELLE BRASIL E ESTADOS UNIDOS}

\section{REFERÊNCIAS}

BARDIN, Laurence. Análise de conteúdo. São Paulo: Edições 70, 1997.

BOAS, Sergio Vilas. O estilo Magazine - o texto em revista. Editora Summus, São Paulo, 1996.

BUITONI, Dulcília Schroeder. Imprensa Feminina. Ed. São Paulo: Ática, 1990.

BRAGA, João. Reflexões sobre Moda. São Paulo: Anhenbi Morumbi, 2006.

CUSTÓDIO, José de Arimathéia; SOUZA, Valdete. Fotografia: meio e linguagem dentro da moda. Discursos Fotográficos, Londrina, 2005.

ELLE MAGAZINE. Disponível em: <http://www.elle.com/>. Acesso em: 16 dez. 2014.

ELLE BRASIL. Disponível em: <http://elle.abril.com.br/>. Acesso em: 16 dez. 2014.

HINERASKY, D.A. Jornalismo de Moda: Questionamentos da cena brasileira. Brasília.

Anais São Paulo, 2010.

JOFFILY, Ruth. O jornalismo e Produção de Moda. Editora Nova Fronteira, Rio de Janeiro, 1991.

LIPOVETSKY, Gilles. O império do efêmero: a moda e seu destino nas sociedades

modernas.São Paulo, SP: Companhia de Letras, 1994.

MARCONDES FILHO, Ciro. Comunicação e Jornalismo - A Saga dos Cães Perdidos. Editora Hacker Editores, 2002.

MELO, José Marques de. Jornalismo Brasileiro. Editora Sulina, São Paulo, 2003.

MIRA, Maria Celeste. O leitor e a banca de revista. Editora Olho D’agua. 2001.

PIOVAN, Marco; NEWTON, Cesar. Making Of. Revelações sobre o dia-a-dia da fotografia. São Paulo: Futura, 2003.

PRODANOV, Cleber Cristiano. Manual de Metodologia Científica. $3^{\text {a }}$ ed. Novo Hamburgo, RS: Feevale,

ROSSI, Clóvis. O que é jornalismo. Editora Brasiliense, São Paulo, 2000.

SIEGEL, Eliot. Curso de fotografia de moda. Tradução Gustavo Gili, SL, Barcelona, 2008.

SCALZO, Marília. O Jornalismo de Revista. Editora Contexto, 2004 e 2011.

TREPTOW, Doris. Inventando Moda: planejamento de coleção. $3^{\mathrm{a}}$ ed. Brusque, SC. Ed. do autor, 2005.

WILSON, Elizabeth. Enfeitada de sonhos: moda e modernidade. Rio de Janeiro: Edições $70,1985$.

\section{RECEBIDO EM: 12/03/2015}

\section{ACEITO PARA PUBLICAÇÃO: 01/08/2015}




\section{Cristiano Max Pereira Pinheiro}

Doutor em Comunicação Social pela PUCRS; coordenador dos cursos de Jornalismo, Relações Públicas e Publicidade e Propaganda e professor do Mestrado em Indústria Criativa da Universidade Feevale.

\section{Christine Bahia Oliveira}

Doutora em Comunicação Social (PUCRS); professora nos cursos de Jornalismo, Relações Públicas e Publicidade e Propaganda (Universidade Feevale).

\section{Patrícia Sodré Costa}

Graduada em Jornalismo (Universidade Feevale).

\section{Milena Cherutti}

Graduanda em Moda (Universidade Feevale); bolsista de pesquisa do CNPq. 
